\title{
Identification of conserved genes triggering puberty in European sea bass males (Dicentrarchus labrax) by microarray expression profiling
}

\author{
Mercedes Blázquez ${ }^{1,2^{*}}$ (D) Paula Medina ${ }^{1,2,3}$, Berta Crespo ${ }^{1,4}$, Ana Gómez $^{1}$ and Silvia Zanuy ${ }^{1 *}$
}

\begin{abstract}
Background: Spermatogenesis is a complex process characterized by the activation and/or repression of a number of genes in a spatio-temporal manner. Pubertal development in males starts with the onset of the first spermatogenesis and implies the division of primary spermatogonia and their subsequent entry into meiosis. This study is aimed at the characterization of genes involved in the onset of puberty in European sea bass, and constitutes the first transcriptomic approach focused on meiosis in this species.

Results: European sea bass testes collected at the onset of puberty (first successful reproduction) were grouped in stage I (resting stage), and stage I| (proliferative stage). Transition from stage I to stage II was marked by an increase of 11 ketotestosterone $(11 \mathrm{KT})$, the main fish androgen, whereas the transcriptomic study resulted in 315 genes differentially expressed between the two stages. The onset of puberty induced 1) an up-regulation of genes involved in cell proliferation, cell cycle and meiosis progression, 2) changes in genes related with reproduction and growth, and 3) a down-regulation of genes included in the retinoic acid (RA) signalling pathway. The analysis of GO-terms and biological pathways showed that cell cycle, cell division, cellular metabolic processes, and reproduction were affected, consistent with the early events that occur during the onset of puberty. Furthermore, changes in the expression of three RA nuclear receptors point at the importance of the RA-signalling pathway during this period, in agreement with its role in meiosis.
\end{abstract}

Conclusion: The results contribute to boost our knowledge of the early molecular and endocrine events that trigger pubertal development and the onset of spermatogenesis in fish. These include an increase in $11 \mathrm{KT}$ plasma levels and changes in the expression of several genes involved in cell proliferation, cell cycle progression, meiosis or RA-signalling pathway. Moreover, the results can be applied to study meiosis in this economically important fish species for Mediterranean countries, and may help to develop tools for its sustainable aquaculture.

Keywords: Spermatogenesis, Cell cycle, Meiosis, Retinoic acid, Teleosts

\footnotetext{
*Correspondence: blazquez@icm.csic.es; s.zanuy@csic.es

'Instituto de Acuicultura de Torre la Sal, Consejo Superior de Investigaciones

Científicas (IATS-CSIC), Ribera de Cabanes, 12595 Castellón, Spain

Full list of author information is available at the end of the article
} 


\section{Background}

Puberty in fish, as in other vertebrates, comprises the developmental process during which an immature individual acquires for the first time the ability to undergo sexual reproduction $[1,2]$. In teleost males, puberty is tightly regulated and implies the proliferation and division of spermatogonia (mitotic phase), their subsequent entry into meiosis with the appearance of spermatocytes (meiotic phase), and the final formation of the spermatids and the haploid mature spermatozoa [2, 3]. A species-specific number of genetically determined divisions characterize the mitotic phase [3], whereas the meiotic phase remains under the influence of the retinoic acid (RA) signalling pathway [4, 5]. Somatic Sertoli cells are important players during spermatogenesis, exhibiting a high mitotic activity, particularly at the beginning of each seasonal cycle [2], and are essential for the proliferation and differentiation of germ cells [6]. Mitosis and meiosis reveal thus as key processes for the onset of puberty in vertebrates. Meiosis is of particular importance since it implies the recombination and reduction of the genetic material, essential to ensure the correct formation of gametes, and therefore guarantees the reproduction and maintenance of the species.

Spermatogenesis is marked by the functional stimulation of the brain-pituitary-gonad (BPG) axis, responsible for its neuroendocrine control [7]. The brain is the central organ that integrates the circuits that sense the internal and external stimuli and secretes different neuropeptides that control the production of gonadotropins from the pituitary. It is generally accepted that gonadotropins (follicle stimulating hormone; Fsh and luteinizing hormone; Lh), and androgens are the main internal stimuli for vertebrate spermatogenesis. Both gonadotropins become activated by a number of factors among which the metabolic status of the individual, in terms of body size and visceral fat content, or the photoperiod, are worth mentioning $[1,2,8,9]$. 11ketotestosterone $(11 \mathrm{KT})$ is the main androgen in fish and plays an important role in the progression of spermatogenesis [10]. It is involved in the proliferation of spermatogonia towards meiosis [11] and mediates the action of several factors produced by Sertoli cells like antimüllerian hormone (Amh) and insulin-like growth factors (Igfs) at the start of the cycle [12]. In addition, Fsh has been shown to stimulate $11 \mathrm{KT}$ production in several fish species [13-17]. In fact, Fsh receptor is present not only in Sertoli cells but also in Leydig cells, the somatic cells with steroidogenic capability, as shown in Senegalese sole [13] African catfish [14] and zebrafish [15-17].

The European sea bass (Dicentrarchus labrax) is an important fish species for marine aquaculture that after intense research on its reproductive function has become a model for both basic and applied research. A number of studies focused on the endocrine control of reproduction shed light on the process and aided to develop protocols for its control in captivity (reviewed by [1]). Increased growth rates under intensive culture resulted in precocious puberty in about $20-30 \%$ of males by the end of the first year of life [18], something that in normal conditions occurs during the second year [19]. As in other farmed fish, precocious maturation is one of the main drawbacks for its culture [9], resulting in important economic losses since by the time of marketing during the second year, precocious males exhibit a smaller size than that of normal-maturing males [20,21]. Several studies have shown that this problem can be partially solved by a well-planned strategy of photoperiod control $[18,21-23]$, although clearly, more work is needed to understand why males mature precociously. Brain factors including kisspeptins [24-27], gonadotropin-releasing hormones (Gnrhs) [28, 29], leptin and their receptors [8] have been characterized in this species. Regarding pituitary gonadotropins, both Fsh and Lh receptors have been cloned [30], and different assays are currently available to measure Fsh and Lh levels in plasma and pituitary [31-33]. Moreover, recombinant European sea bass gonadotropins have been used as a biotechnological approach in gene therapy for assisted reproduction [34, 35]. In addition, secretion patterns of sex steroids [36], sex steroid receptors, and several steroidogenic enzymes [30, 37] during the seasonal cycle have also been reported.

Despite all the previous knowledge, little is known about the molecular machinery that triggers puberty in European sea bass males, apart from a study reporting the possible involvement of several genes in the early events preceding gonadal maturation [38]. The recent availability of several molecular resources, including a partially annotated European sea bass genome database [39] gave us the opportunity to study this process using a high throughput strategy. The aim of the present work is to compare the transcriptome from European sea bass testes before and right at the start of puberty, and to identify potential genes and pathways involved in the process. This will boost our knowledge of the onset of pubertal development from a basic perspective and will help to implement tools for the improvement of a sustainable aquaculture.

\section{Methods}

\section{Animals, rearing conditions and samplings}

European sea bass hatched in April 2008 at the Ecloserie Marine de Gravelines (EMG) in the North of France and were grown there until 100 days post hatching (dph) when they were transported to our aquaria facilities at the Institute of Aquaculture Torre la Sal (IATS), a research centre belonging to the Spanish National 
Research Council (CSIC) in the Spanish Mediterranean coast. The facilities were approved for animal experimentation by the Ministry of Agriculture and Fisheries and by the Department of Fisheries from the Generalitat Valenciana (certificate number ES120330001055). Fish were reared in $2000 \mathrm{l}$ round fiberglass tanks under natural conditions of photoperiod and temperature until the end of the experiment. In December 2008, coinciding with the first breeding season in this species, fish were subjected to abdominal massage to check for the presence of sperm. This allowed us to eliminate males exhibiting precocious puberty that could interfere with our results. These procedures were repeated every 20 days for a period of about 3 months. Prior to the start of the second breeding season (August 2009), coinciding with European sea bass normal puberty, a sampling procedure was designed to obtain testes covering the first stages of spermatogenesis. Samplings (15 fish per sampling point) were performed every 10 days starting in mid-August and finishing by the end of October. At each sampling point, fish were anesthetized with 2phenoxyethanol $\left(0.2 \mathrm{ml} \cdot \mathrm{l}^{-1}\right)$ and blood was taken from the caudal vein for plasma sex-steroid measurements. Fish were subsequently sacrificed by quickly severing their spinal cord and gonads were dissected for histology (the central part of the gonad) whereas the rest was kept at $-80{ }^{\circ} \mathrm{C}$ for further RNA extractions needed for the different analyses including microarray hybridizations, validations, and tissue specific expression studies. Fish were treated in agreement with the Spanish regulations (Royal Decree Act 53/2013) and the European legislation (2010/63 EU) concerning the protection of animals used for experimental and other scientific purposes. All steps were taken to reduce suffering of the animals.

\section{Histological analysis}

After dissection, the central part of the testes was immediately fixed in $4 \%$ formaldehyde: $1 \%$ glutaraldehyde in phosphate buffered saline (PBS; [40]). Tissues were washed in PBS and dehydrated in an increasing series of ethanol 70-96\%. Samples were embedded in glycol methacrilate resin (Technovit 7100; Heraeus, Kulzer, Germany), sectioned at 3-4 $\mu \mathrm{m}$, and stained as in [41]. The stages of testicular development and the type and abundance of germ cells in each stage were assessed according to [18] and [42], respectively.

\section{Steroid analysis by enzyme immune assay (EIA)}

Plasma levels of $11 \mathrm{KT}$ were determined by enzyme immune assay (EIA) in 20 fish selected from each developmental stage, using the protocol by [22]. Briefly, antibodies were used at a final concentration of $1: 200,000$ and the tracer (Cayman chemicals, MI, USA) was diluted at 1:50 Ellman Units (UE)/ml (used at $0.1042 \mathrm{EU} / \mathrm{ml}$ ). The sensitivity of the assay was around $0.003 \mathrm{ng} / \mathrm{ml}(\mathrm{Bi} / \mathrm{B} 0=90 \%)$ and half displacement $(\mathrm{Bi} / \mathrm{B} 0=50 \%)$ occurred around $0.03 \mathrm{ng} / \mathrm{ml}$ (slope $=-1.018)$. The inter-assay coefficient of variation ( $n=2$ plates) was $1.72 \%$.

\section{RNA isolation and CDNA synthesis}

For hybridizations and real-time validations, testes (approx. 50-100 mg) were homogenized in Trizol (Invitrogen, Carlsbad, CA) using the FastPrep ${ }^{\circ}$ Instrument (Qbiogene, Inc., Carlsbad, CA), a tissue homogenizer with ceramic spheres as a lysing matrix. Total RNA was extracted from the lysate with the PureLink ${ }^{\text {ni }}$ RNA mini Kit (Invitrogen), following the manufacturer's instructions. Briefly, RNA was phase separated, washed, and finally eluted in DEPC water. For the tissue-distribution study, tissues including telencephalon, hypothalamus, cerebellum, spleen, gills, head kidney, kidney, liver, testis, ovary, heart and gut were homogenized in a thioglycerol-based buffer included in the Maxwell ${ }^{\circ} 16$ LEV simplyRNA tissue kit (Promega, Madison, WI). The homogenates were used for RNA isolation with the Maxwell 16 instrument (Promega) following the manufacturer's instructions that include a DNase treatment. Nevertheless, an additional test was done on the RNAs to discard any possible DNA contamination. For microarray hybridizations RNA quality was assessed with a Bioanalyzer 2100 (RNA 6000 Nano LabChip kit Agilent, Spain) and only RNAs with RIN values higher than 8.5 were used. For other downstream applications such as quantitative real time PCR (qPCR) or conventional PCR (tissue expression study), RNA quantification was done with a Nanodrop 2000c (Thermo Scientific, Wilmington, DE) and stored at $-80{ }^{\circ} \mathrm{C}$ until further cDNA synthesis. Total RNA $(3 \mu \mathrm{g})$ was reverse transcribed to cDNA with Superscript III (Invitrogen) and random hexamers following the manufaturer's instructions. Protection of RNA from ribonucleases during cDNA synthesis was done by including 40 units of RNAse inhibitors (RNasin, Promega). The reaction was inactivated at $70{ }^{\circ} \mathrm{C}$ for $15 \mathrm{~min}$.

\section{Microarray hybridization and analysis}

RNA labelling, hybridizations, and scanning were performed at the Autonomous University of Barcelona (UAB). Total RNA (100 ng) was amplified and Cy3labeled with One-Color Microarray Gene Expression Analysis (Low Input Quick Amp Labelling kit, Agilent) along with One-Color RNA SpikeIn Kit (Agilent) following the manufacturer's instructions. The resulting cRNA was purified (RNeasy mini spin columns; Qiagen), quantified with a Nanodrop ND-1000 and checked with a Bioanalyzer 2100 as previously described. Amplified 
samples (1.65 $\mu \mathrm{g}$ per sample) were hybridized to a custom oligonucleotide high-density European sea bass microarray (Agilent $4 \times 44 \mathrm{~K}$ design format; http:// www.agilent.com/) containing 60-mer oligonucleotides with a linker directly spotted on glass slides using the Agilent's SurePrint Tecnology. Three samples from each testicular stage, selected after histological examination and $11 \mathrm{KT}$ plasma levels, were used for microarray hybridizations, each of them consisting of a pool RNAs from six males. The pools were used as biological replicates and thus independent samples for microarray hybridizations. In addition, and since each microarray plate can hold up to four samples $(4 \times 44$ design), one sample from each stage was randomly chosen and hybridized in both plates as a quality control to check for possible inter-plate hybridization differences. The probes contained in the microarray (GEO accession number GPL13443) cover 13,199 unique sequences of Dicentrarchus labrax that include 6275 annotated transcripts, each with 3 specific probes, and 6924 ESTs with 1 probe/target sequence. Assuming that a typical diploid teleost genome is expected to have 26-28 thousand protein coding loci, the microarray used for the study should cover about half of the genes of the species. Hybridizations were done at $65{ }^{\circ} \mathrm{C}$ for $17 \mathrm{~h}$ (GE Hybridization Kit; Agilent). Washes were conducted as recommended by the manufacturer using Agilent's Gene Expression Wash Pack with stabilization and drying solution and arrays were scanned with a G2505B (Agilent). Several quality control features and spot intensities were extracted with Agilent's Feature Extraction software v10.4. Finally, data were analyzed with GeneSpring software v10.1. Percentile shift normalization was used to adjust all spot intensities in the array (percentile target $=75)$. Principal Component Analysis (PCA) was used as a quality control on samples and allowed to decrease the number of false positives before the statistical analysis. Normalized data were filtered by comparison of the standard deviation expression among groups (filter by expression). Statistical analyses were performed on filtered data using a t-test. Significant differences in the transcriptomic profile between early stages of spermatogenesis (data filtered at a fold change (FC) expression of 2 ) were set at $p<0.01$. The corresponding study was deposited at the Gene Expression Omnibus (GEO-NCBI) database under the accession number GSE47400.

\section{Gene annotation and enrichment analysis}

The web-based tools Genecards (http://www.genecards.org), Uniprot (http://www.uniprot.org) and AmiGO 2 (amigo.http://amigo.geneontology.org) were used to assign gene names, synonyms and functions to the differentially expressed genes (DEGs) found after microarray hybridizations. The annotation of the sequences was manually curated, improving the accuracy of the information obtained from the microarray used for this study. A further improvement was added implementing the Blast2Go software [43] that enriched the number of GO-term annotations. A list containing all genes included in our custom-made microarray was used as a reference set to evaluate the enrichment in GO-terms in the subset of DEGs. The resulting data were analysed with Fisher's exact test with multiple testing correction of the false discovery rate. In addition, annotated DEGs were ascribed to functional biological pathways using the Kyoto Encyclopaedia of Genes and Genomes (http:// www.genome.jp/kegg) and the possible altered metabolic pathways were assessed.

\section{Array validation by quantitative real-time PCR (qPCR)}

EST sequences of the DEGs were used as a query in Blast searches against the European sea bass genome and GeneBank databases in order to position the selected DEGs in their corresponding genes. Primers for the amplification of the DEGs were designed in areas covering intron-exon boundaries to check for genomic contamination using Primer 3 (http://primer3.ut.ee). Primers (Additional file 1) were checked by conventional PCR and the amplified fragments sequenced to verify their identities. qPCR analyses were performed with an iCycler $\mathrm{iQ}^{\mathrm{ix}}$ (BioRad Labs., Inc.) using $\mathrm{SYBR}^{\circ}$ Green (PCR Master Mix; Applied Biosystems). PCR reactions were run in triplicate in optically clear 96 -well plates in a final $20 \mu \mathrm{l}$ volume containing $10 \mu \mathrm{l}$ of $2 \times$ Sybr Green Master mix, 10 pmol of each primer and $5 \mu$ lof diluted cDNA (1:50 for the target genes or 1:500 for the reference gene). Cycling parameters included an initial denaturation at $95{ }^{\circ} \mathrm{C}$ for $3 \mathrm{~min}$, followed by 40 cycles at $95{ }^{\circ} \mathrm{C}$ for $15 \mathrm{~s}$ and annealing-extension at $60-72{ }^{\circ} \mathrm{C}$ for $1 \mathrm{~min}$ ending with an extension at $72{ }^{\circ} \mathrm{C}$ for $1 \mathrm{~min}$. A final temperature dissociation step was done to ensure the presence of just one product. qPCR data were collected with iCycler ${ }^{\mathrm{Tn}}$ iQ optical system software (v. 3.0, BioRad). The cycle threshold (Ct) was calculated as the average of three replicates per sample. Gene expression analyses were conducted using the Q-Gene core module [44]. Briefly, for each gene the amplification efficiency (E) was calculated from the slope of the linear correlation between Cts and the logarithm of the amount of serially diluted RNA, used as a standard, following the eq. $\mathrm{E}=10^{(-1 / \text { slope })}$. $\mathrm{E}$ values for the different genes were within the range of $93.5-101.8 \%$. Values were normalized (normalized expression; NE) to the constitutively expressed reference gene $18 S$ rRNA in each sample ( $n=8$ individual fish per stage and gene) according to the eq. $\mathrm{NE}=\left(\mathrm{E}_{\mathrm{ref}}\right)^{\mathrm{Ctref}} /\left(\mathrm{E}_{\text {target }}\right)^{\mathrm{Cttarget}} .18 S \mathrm{rRNA}$ was considered a good reference gene since it exhibited the best bestkeeper index when comparing different 
developmental stages [45]. In addition, the expression of this gene remains constant in many physiological conditions such as differentiation and proliferation [46] making it a suitable reference gene for this study.

\section{Tissue specific expression}

The expression of the selected DEGs was assessed in different tissues including telencephalon, hypothalamus, cerebellum, spleen, gills, head kidney, kidney, liver, testis, ovary, heart and gut. PCR reactions were performed with an initial denaturation of $5 \mathrm{~min}$ at $94{ }^{\circ} \mathrm{C}$, and then 34 cycles with the following characteristics: denaturation at $94{ }^{\circ} \mathrm{C}$ for $30 \mathrm{~s}$, annealing at $60{ }^{\circ} \mathrm{C}$ for $30 \mathrm{~s}$, and extension at $72{ }^{\circ} \mathrm{C}$ for $30 \mathrm{~s}$. A final extension of $2 \mathrm{~min}$ at $72{ }^{\circ} \mathrm{C}$ was added at the end of the 34 cycles.

\section{Sequencing, cloning, and phylogenetic studies of European sea bass cyp26a1}

Based on the ESTs of the microarray, the full sequence of European sea bass cyp26a1 was localized along the genome. Specific primers were designed in $3^{\prime}$ - and $5^{\prime}-$ UTR flanking regions to amplify its full-coding sequence. The fragment was cloned into a bacterial vector using the pGEM T-easy cloning kit (Promega Corp., Madison, WI), and amplified in E. coli competent cells following the manufacturer's instructions. Several colonies were selected, grown in liquid LB and finally sequenced with an automatic ABI 3100 Genetic Analyser (Applied Biosystems, Foster City, CA), using the BigDye Terminator v3.1 Cycle Sequencing Kit (Applied Biosystems). The identity of the clones was confirmed after sequencing, multiple alignment comparisons, and phylogenetic analysis. An in silico study of the $5^{\prime}$ upstream $1500 \mathrm{bp}$ of the flanking promoter sequence using MatInspector and (Promo) Transfac v.8.3 was used to identify the presence of putative binding sites for transcription factors that could be involved in the activation or repression of cyp26a1 transcription. An alignment of known Cyp26 proteins from vertebrates, either compiled from GenBank/EMBL or predicted in ENSEMBL, was made with clustalW2. For the phylogenetic tree, the distances were computed with the Poisson correction method [47] and the evolutionary history was inferred using the Neighbor-Joining method [48] after a bootstrap test using 1000 replicates. The phylogenetic analysis was carried out in MEGA v.4 [49].

\section{Statistical analyses}

Student's t-test for hormonal analysis, microarray hybridizations and gene expression levels was used to reveal significant differences between stage I and stage II. In all cases, significant differences were accepted at $p<0.05$ except for microarray hybridizations for which differences were accepted at $p<0.01$.

\section{Results}

Sample selection: histological and hormonal classification Sea bass testes were histologically classified according to their stage of spermatogenesis $[18,42]$. Since the study was focussed on the onset of spermatogenesis, only testes in stage I (immature) and stage II (proliferative) were used. Briefly, stage I, corresponded to an immature testis, and was characterized by the presence of type A spermatogonia located within the seminiferous lobules (Fig. 1a). Stage II, corresponded to testis in a proliferative phase and was characterized by the presence of type A spermatogonia, abundant cysts of type B spermatogonia and sometimes cysts of type I spermatocytes (Fig. 1b). Plasma samples from males previously classified by histology as stage I $(n=20)$ or stage II $(n=20)$ were used to check their levels of $11 \mathrm{KT}$. The results showed that $11 \mathrm{KT}$ was a suitable marker to discriminate between males in stage I and stage II with significantly higher levels in the latter than the former (Fig. 2). Based on that, testes from 18 males in stage I (11KT levels ranging between 0.35 and $0.87 \mathrm{ng} / \mathrm{ml})$, and 18 males in stage II (11KT levels ranging between 2.18 and $3.64 \mathrm{ng} / \mathrm{ml}$ ) were

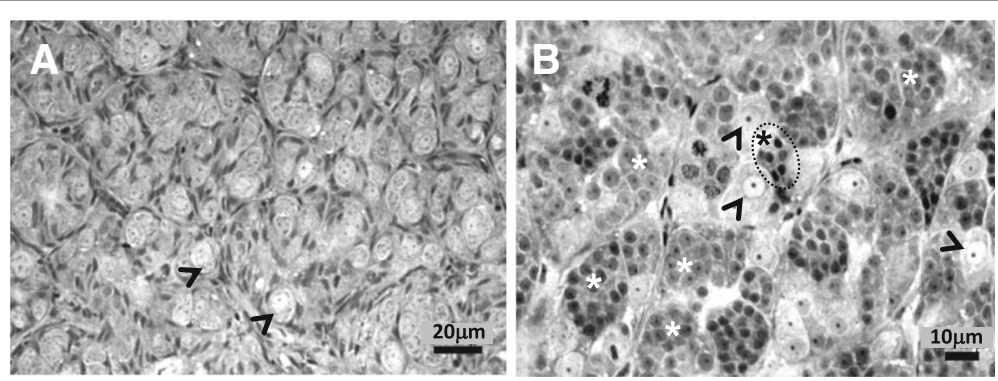

Fig. 1 Photomicrographs of European sea bass testis during early stages of pubertal development. a Sexually immature testis in stage I, was characterized by the presence of type A spermatogonia (arrowheads) located within the seminiferous lobules (b) Early recrudescent testis in stage II, characterized by the presence of type A spermatogonia (arrowheads), abundant cysts of type B spermatogonia (white asterisks), and scarce cysts of type I spermatocytes (encircled black asterisk) 


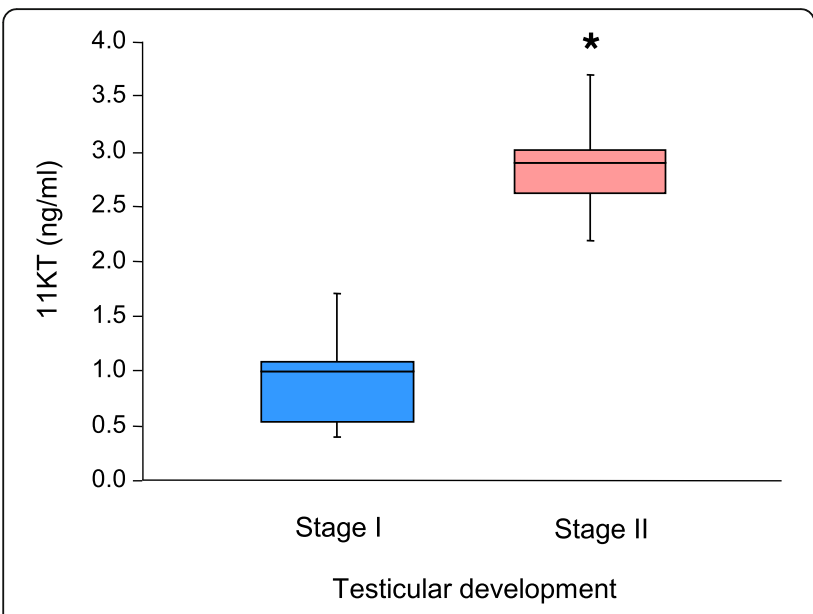

Fig. 2 Box-and-whisker plots of 11 ketotestosterone (11 KT) plasma levels in European sea bass males during early stages of puberty. 11KT levels were measured at two different stages of pubertal development: stage I, corresponding to sexually immature testes and stage II corresponding to early recrudescent testes. Box represents uper and lower quartiles and maximum and minimum observed values are represented by whiskers. Horizontal line represents the median value $(0.99 \mathrm{ng} / \mathrm{ml}$ for stage I and $2.90 \mathrm{ng} / \mathrm{ml}$ for stage II). The asterisk denotes statistical differences between both groups after a student t-test $(p<0.05) ; n=20$ in each experimental group

selected for further RNA extractions and microarray hybridizations. For that purpose, the RNAs from the 18 males of each testicular stage were randomly divided and pooled into six groups, three corresponding to stage I and the other three to stage II. The pools of each stage consisted of the RNA from six different fish of that particular stage up to 18 fish per stage. The pools were used as biological replicates and thus independent samples for microarray hybridizations.

\section{Microarray hybridizations}

Changes in gene expression during the onset of spermatogenesis (stage I versus stage II) were assessed with a European sea bass specific microarray previously described and validated (GPL13443). The study identified 315 DEGs between the two spermatogenic stages (FC > 2), among which 162 corresponded to functionally annotated genes whereas the remaining 153 were nonannotated sequences. When comparing their expression, a similar number of DEGs were found to be upregulated and downregulated (150 upregulated versus 165 downregulated; see Additional file 2 for a list of all DEGs and Additional file 3 for a glossary of the genes involved in cell proliferation, reproduction, growth and RA-signalling pathway with particular mention in this study). A PCA showed the spatial distribution of the microarray data and revealed the presence of two clear clusters, one corresponding to stage I testes and the other one to stage II testes (Additional file 4). Component 1 explained $92.43 \%$ of the variation whereas component 2 was responsible for $5.13 \%$ of the variation. In addition, a heatmap representation of the DEGs grouped fish according to their stage of testicular development (Fig. 3).

A Gene Ontology (GO) study of the DEGs of the microarray resulted in a distribution among the three main functional categories including biological processes (Additional file 5A) with a high presence of genes involved in cell division, cell cycle, cell differentiation and cytoskeleton organization typical of the increased cell proliferating activity during early testicular recrudescence. In addition, genes involved in growth, reproduction, metabolism and catabolism were also differentially expressed. Regarding the molecular function (Additional file 5B), binding, enzymatic activity, and transport were differentially regulated. As for the cell component (Additional file $5 \mathrm{C}$ ), a majority of the processes appeared taking place in the nucleus and were linked to the protein complex. These results were supported by a GO enrichment analysis that resulted in the identification of several DEGs in the major functional categories undergoing changes throughout European sea bass spermatogenesis (Table 1). Three main subsets were apparent, one including several biological processes focused on reproduction, cell cycle, cell division, chromosome segregation and cellular metabolic processes; a functional subset related to binding; and finally a cellular component category mainly related to processes taking place in the nucleus. The fact that cell cycle processes occur mainly in the nucleus suggests that both subsets are mechanistically related and are involved in cell division and progression. The analysis of the affected biological pathways during the onset of pubertal development (Table 2) indicated that 15 of the DEGs $(>2.0 \mathrm{FC})$ were involved in metabolic pathways mainly related to nucleotide, amino acid and lipid metabolism and retinol metabolism. Pathways involved in cellular processes mainly cell cycle, meiosis, and DNA replication and repair were also affected, and included 13 DEGs. Other group of DEGs was involved in different signalling pathways and the last group includes pathways related with the endocrine system.

\section{Microarray validations}

For qPCR validations of the microarray results, several DEGs representing different categories of interest were selected according to their relevance in reproduction. All of them were cloned and sequenced to confirm their identity. The relative differential expression was assessed for 14 transcripts. Six of them (pcna, cenpi, spc25, cenpf, trip13, $c d c 28$ ), were included in a group of genes with special relevance in cell proliferation and cell cycle progression (Fig. 4a). Five transcripts (aqp1, amh, sgII, agrp2, igfbp6) were included in the group of genes with relevance in reproduction and growth (Fig. 4b). The remaining three transcripts (cyp26a1, rbp4, crabp1) were 


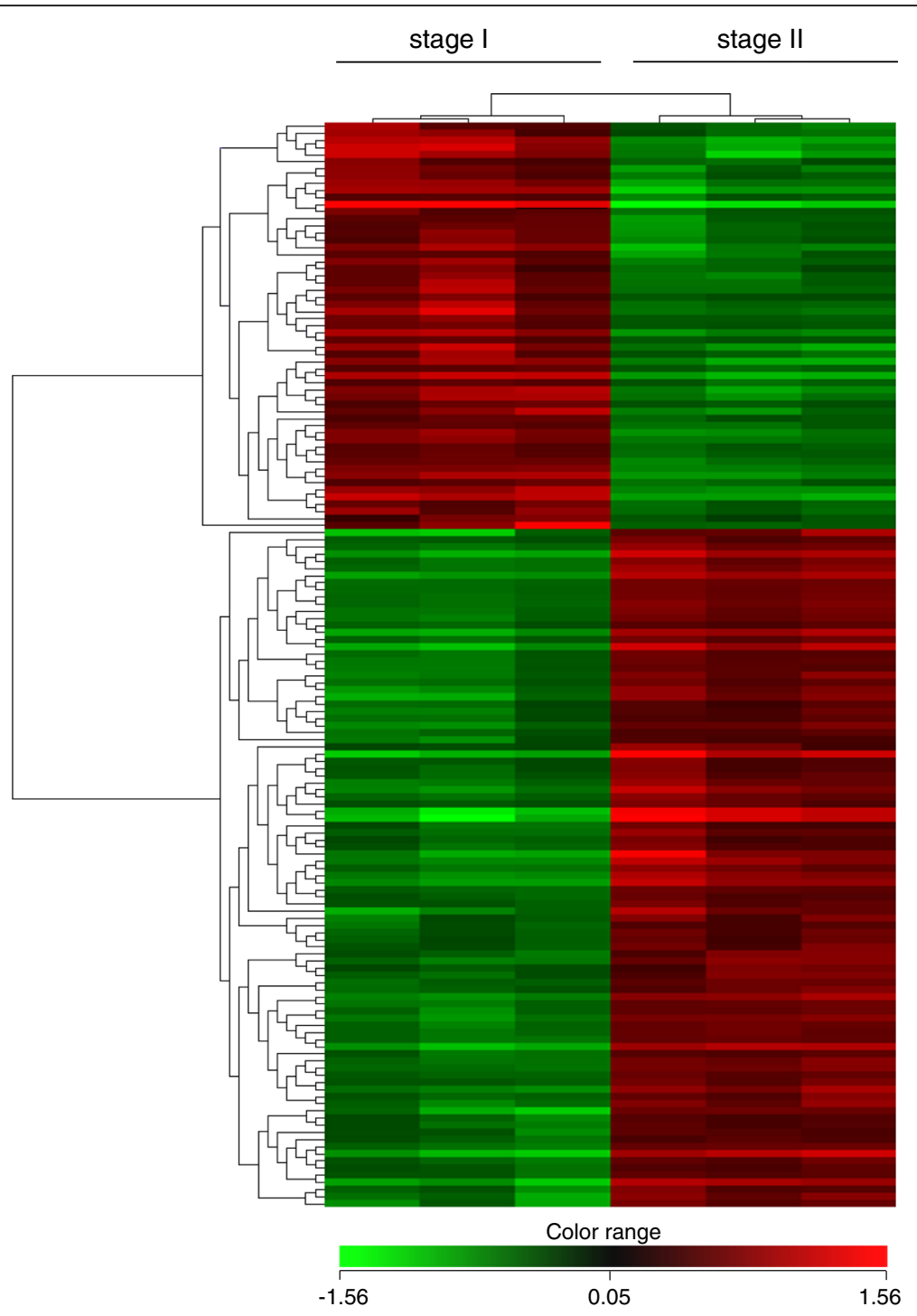

Fig. 3 Hierarchical heat map of European sea bass annotated ESTs differentially expressed during early stages of puberty. The individual genes are pictured horizontally showing their relative expression values across all replicates of the different stages of pubertal development (tree replicates per stage) that are represented in each column. The colour scheme is calibrated to the log2 expression values with red representing higher transcript abundance and green lower transcript abundance. The heatmap displays only DEGs (corresponding to 152 annotated genes) with significantly different expression values $(p<0.01)$ between stage I and stage II and a log2 fold change value greater than two (Pearson correlation). The scale bar shows Z-score values

located in the group of genes involved in the RAsignalling pathway (Fig. 4c). In addition, and due to their prominent role in that pathway, the expression of three more transcripts, corresponding to RA-nuclear receptors (rara, rxro and ppary) was studied in stage I and stage II testis (Fig. 4c). The stage-specific expression levels were normalized to those of the constitutively expressed $18 \mathrm{~S}$ rRNA gene in each sample. The qPCR results were consistent and showed a good correlation with those of the microarray data (Fig. 5). It is worth mentioning that in a number of genes, the microarray results exhibited lower differences between the two developmental stages than those found from the qPCR, indicating that this particular microarray may represent an underestimate of the extent of differential expression during European sea bass spermatogenesis (Additional file 6).

\section{Molecular cloning of European sea bass cyp26a1 and phylogenetic analysis}

Among the DEGs found in the microarray we focused on cyp26a1 due to its prominent role in the RA signalling pathway by maintaining the homeostasis of intracellular RA levels [50] and because RA is known to be essential for the onset of meiosis in several vertebrates 
Table 1 Gene ontology analysis of annotated transcripts significantly affected during the onset of puberty in European sea bass testis (Fisher's exact test with multiple corrections for FDR)

\begin{tabular}{|c|c|c|c|c|c|}
\hline GO-term & FDR & $P$-value & $\begin{array}{l}\text { Sample frequency } \\
(N=141)\end{array}$ & $\begin{array}{l}\text { Array frequency } \\
(N=7681)\end{array}$ & Gene names \\
\hline \multicolumn{6}{|l|}{ Biological process } \\
\hline GO:0007049. Cell cycle & $2.0 \mathrm{E}-7$ & $2.3 \mathrm{E}-10$ & $36(25.5 \%)$ & $594(7.7 \%)$ & $\begin{array}{l}\text { uhrf2, dmc1, nsl1, ccnd2, kif2c, cenpi, thbs 1, jmy, } \\
\text { chaf16, psmd3, ncapg, rbbp4, syce1, ttk, sycp2, } \\
\text { pold3, camk2d, ndc80, aspm, rad9b, aurkb, psmb7, } \\
\text { bub3, dtymk, ppef1, cenph, anln, slbp, spc25, nup37, } \\
\text { mad211bp, ccne2, trip13, cdc28, nsmce2, cenpf }\end{array}$ \\
\hline GO:0051301. Cell division & $3.8 \mathrm{E}-2$ & $2.2 \mathrm{E}-3$ & $11(7.8 \%)$ & $212(2.8 \%)$ & $\begin{array}{l}\text { nup } 37, \text { nsmce2, anl, aurkb, cenph, aspm, ndc80, } \\
\text { mad2libp, bub3, ppef1, cdc28 }\end{array}$ \\
\hline $\begin{array}{l}\text { GO:0007059. Chromosome } \\
\text { segregation }\end{array}$ & $2.1 \mathrm{E}-6$ & $2.1 \mathrm{E}-08$ & $12(8.5 \%)$ & $70(1.0 \%)$ & $\begin{array}{l}\text { nup37, nsmce2, aurkb, cenph, ndc80, kif2c, madl1bp, } \\
\text { cenpf, ttk, bub3, sycel, ncapg }\end{array}$ \\
\hline $\begin{array}{l}\text { GO:0006259. DNA metabolic } \\
\text { process }\end{array}$ & $8.0 \mathrm{E}-3$ & $6.0 \mathrm{E}-5$ & $20(14.2 \%)$ & $401(5.2 \%)$ & $\begin{array}{l}\text { uhrf2, dmc1, cacybp, jmy, chafib, pcna, ncapg, } \\
\text { rbbp4, pold3, rfc3, rad9b, cry2, smarcc2, asfib, fen1, } \\
\text { trip13, ruvbl2, nt5e, mcm3, nsmce2 }\end{array}$ \\
\hline GO:0010467. Gene expression & $2.0 \mathrm{E}-7$ & $2.6 \mathrm{E}-10$ & $4(2.8 \%)$ & $1658(21.6 \%)$ & uhrf2, thbs 1, eed, asfib \\
\hline GO:0000003. Reproduction & $2.3 \mathrm{E}-2$ & $4.9 \mathrm{E}-04$ & $14(9.9 \%)$ & $266(3.5 \%)$ & $\begin{array}{l}\text { tgfbr1, adamts1, cenpi, bub3, sycel, ihh, sycp2, } \\
\text { dmc1, hsf2bp, amh, trip13, sdf1a, ttk, fosla }\end{array}$ \\
\hline $\begin{array}{l}\text { GO:0044237. Cellular metabolic } \\
\text { process }\end{array}$ & $2.1 \mathrm{E}-3$ & $1.2 \mathrm{E}-5$ & $47(33.3 \%)$ & $3993(52 \%)$ & $\begin{array}{l}\text { uhrf2, dmc1, rab6a, hck, cacybp, thbs 1, jmy, } \\
\text { chaf1b, pcna, psmd3, ncapg, cry2, gpd1, cad, } \\
\text { rbbp4, nme1, ttk, pold3, camk2d, rfc3, lox, srsf7, } \\
\text { rad9b, eed, ifitm2, fen1, smarcc2, asf1b, nme3, } \\
\text { aurkb, shmt1, cpsf3, atp6voe1, dtymk, nsmce2, } \\
\text { ppef1, u2af35, slbp, trip13, Inxi, fkbp8, nnt, } \\
\text { ruvbl2, tgfbr1, nt5e, ubr7, mcm3 }\end{array}$ \\
\hline $\begin{array}{l}\text { GO:0050794. Regulation of cellular } \\
\text { process }\end{array}$ & $1.1 \mathrm{E}-2$ & 8.7E-5 & $29(20.6 \%)$ & $2774(36.1 \%)$ & $\begin{array}{l}\text { bnc1, ihh, agrp2, rab6a, thbs 1, c-fosla, psmd3, } \\
\text { q2laq1, amh, ect2, cad, trip13, camk2d, ndc } 80, \\
\text { rad9b, stat3, cry2, sdf1a, ppef1, depdc1b, crabp1, } \\
\text { isg20l2, Ibr, ap2s1, cyp26a1,fkbp8, tfrc, adamts1, } \\
\text { tgfbr1 }\end{array}$ \\
\hline \multicolumn{6}{|l|}{ Molecular function } \\
\hline GO:0043169. Cation binding & $2.4 \mathrm{E}-3$ & $1.4 \mathrm{E}-5$ & $8(5.7 \%)$ & $1434(18.7 \%)$ & $\begin{array}{l}\text { ihh, mgp, thbs1, cad, tppp3, ppef1, slc25a25, } \\
\text { anxa2 }\end{array}$ \\
\hline GO:0043167. lon binding & $2.4 \mathrm{E}-3$ & $1.5 \mathrm{E}-5$ & $8(5.7 \%)$ & $1443(18.8 \%)$ & $\begin{array}{l}\text { ihh, mgp, thbs1, cad, tppp3, ppef1, slc25a25, } \\
\text { anxa2 }\end{array}$ \\
\hline GO:0046872. Metal ion binding & $3.2 \mathrm{E}-3$ & $2.1 \mathrm{E}-5$ & $8(5.7 \%)$ & $1414(18.4 \%)$ & $\begin{array}{l}\text { ihh, mgp, thbs 1, cad, tppp3, ppef1, slc25a25, } \\
\text { anxa2 }\end{array}$ \\
\hline \multicolumn{6}{|l|}{ Cellular component } \\
\hline GO:0005634. Nucleus & $4.8 \mathrm{E}-2$ & 4.7E-4 & 55 (39.0\%) & $2002(26.1 \%)$ & $\begin{array}{l}\text { bnc1, apeh, uhrf2, dmc1, ihh, ccnd2, cacybp, cenpi, } \\
\text { jmy, c-fosla, chaf1b, pcna, trhb, sh3bgrl3, rbbp4, } \\
\text { sycel, sycp2, pold3, camk2d, rfc3, ndc80, aspm, lox, } \\
\text { srsf7, rad9b, eed, stat3, cry2, smarcc2, asf1b, smox, } \\
\text { aurkb, shmt1, cpsf3, lbr, psmb7, b9d2, bub3, gfi1, } \\
\text { fen1, ass1, ppef1, u2af35, cenph, chrac1, slbp, nup37, } \\
\text { cenpf, mad2l1bp, ccne2, trip13, isg20l2, ruvbl2, mcm3, } \\
\text { cdc28 }\end{array}$ \\
\hline GO:0005694. Chromosome & $3.9 \mathrm{E}-7$ & $6.0 \mathrm{E}-10$ & $25(17.7 \%)$ & $302(3.9 \%)$ & $\begin{array}{l}\text { uhrf2, dmc1, nsl1, kif2c, cenpi, pcna, ncapg, rbbp4, } \\
\text { sycel, pold3, rfc3, ndc80, rad9b, eed, asfib, aurkb, } \\
\text { bub3, u2af35, spc25, nup37, mad2/1bp, ruvbl2, mcm3, } \\
\text { nsmce2, cenpf }\end{array}$ \\
\hline GO:0000228. Nuclear chromosome & $3.5 \mathrm{E}-4$ & $1.6 \mathrm{E}-6$ & $11(7.8 \%)$ & $89(1.1 \%)$ & $\begin{array}{l}\text { dmcl, pcna, rbbp4, syce1, pold3, ndc80, rad9b, eed, } \\
\text { aurkb, ruvbl2, mcm3 }\end{array}$ \\
\hline GO:0016020. Membrane & $2.0 \mathrm{E}-7$ & $2.7 \mathrm{E}-10$ & $14(9.9 \%)$ & $2545(33.1 \%)$ & $\begin{array}{l}\text { bnc1, ihh, thbs1, dsg2, cad, camk2d, slco2a1, } \\
\text { ppef1, rims1, ap2s1, tfrc, tgfbr1, nt5e, synpo }\end{array}$ \\
\hline
\end{tabular}

Genes in bold type correspond to downregulated genes in the microarray whereas up regulated genes appear in normal type 
Table 2 Affected KEGG pathways at the onset of European sea bass puberty

\begin{tabular}{ll}
\hline Pathway name & Genes involved \\
\hline Metabolic pathways & \\
- Nucleotide metabolism & nme3, pold3, cad, tyms, nt5e, dtymk \\
- Retinol metabolism & cyp26a1 \\
- Lipid metabolism & pnpla2, gpd1, agrp2, ptges \\
- Amino acid metabolism & odc1, pycr2, smox, ass1, cad, shmt1, \\
& pah
\end{tabular}

Downregulated genes appear in bold type whereas upregulated genes appear in normal type

[51-54]. The cDNA isolated for European sea bass cyp26a1 contained an ORF 1178 bp long, was flanked by a 500 bp 3'UTR region and was deposited in the GenBank under the accession number KJ187657. The deduced amino acid sequence encodes a protein 488 amino acid long with a theoretical PI of 9.04 and a calculated molecular weight of $55.495 \mathrm{kDa}$. A Genbank search resulted in the identification of several full-length sequences for Cyp26 proteins in teleosts and tetrapods, including amphibians, reptiles, birds and mammals. The phylogenetic analysis showed that the European sea bass protein was evolutionarily closer to CYP26A1 proteins, while it was more distant from other CYP26B1 and CYP26C1 proteins (Fig. 6 and Additional file 7 for accession numbers). The consensus tree had three main branches, one containing all A1 sequences, another one including $\mathrm{B} 1$ sequences and the remaining with $\mathrm{C} 1$ sequences. Sea bass sequence clustered together in the A1 group further supporting its identity. Comparisons of the deduced amino acid sequence with other full-length Cyp26a1 in different fish revealed that the highest homology was shared with stickleback $(94.4 \%)$ and the lowest with zebrafish (82.4\%). These slight differences among fish support that Cyp26a1 in teleosts is quite highly conserved. A study of the $5^{\prime}$ flanking sequence (1500 bp upstream of the first ATG) of the cyp26a1 gene showed the presence of binding sites for different transcription factors among which it is worth mentioning RA-nuclear receptors (Rxr, Rar, and Ppar), steroid receptors, and several elements involved in cell cycle regulation (Additional file 8 ).

\section{Tissue specific expression}

The expression of the selected DEGs and the three extra genes in different tissues was assessed by conventional PCR (Fig. 7). Among the cell proliferation genes, pcna and $s p c 25$ were ubiquitously expressed whereas cenpi expression was mainly restricted to gonads, with highest levels in ovary. Regarding the genes involved in reproduction and growth, aqp1 was expressed at similar levels in all the tissues studied. sgII expression was found in all tissues but with higher levels in pituitary, cerebellum, kidney and testis. The expression of amh was highest in gonads and undetectable in telencephalon and pituitary whereas igfbp 6 expression was restricted to the gills, liver, testis and gut. Finally, the genes involved in RA-signalling pathway were expressed at similar levels in all tissues except cyp26a1 that showed highest expression in gonads and crabp 1 that was mostly expressed in head kidney and at lower levels in dorsal kidney, gills and testis.

\section{Discussion}

The present study contributed to identify differences in gene expression during the early stages of pubertal development in European sea bass males using a custommade microarray. However, and despite the fact that the differences observed at the transcriptome and the steroid level are related to puberty (first successful reproduction), it is possible that similar changes could be found in successive reproductive seasons since they mark the transition between quiescence and the start of gametogenesis. The use of long oligo-based microarrays has been shown to have a higher sensitivity for detection but a lower specificity [55] and therefore could have a 


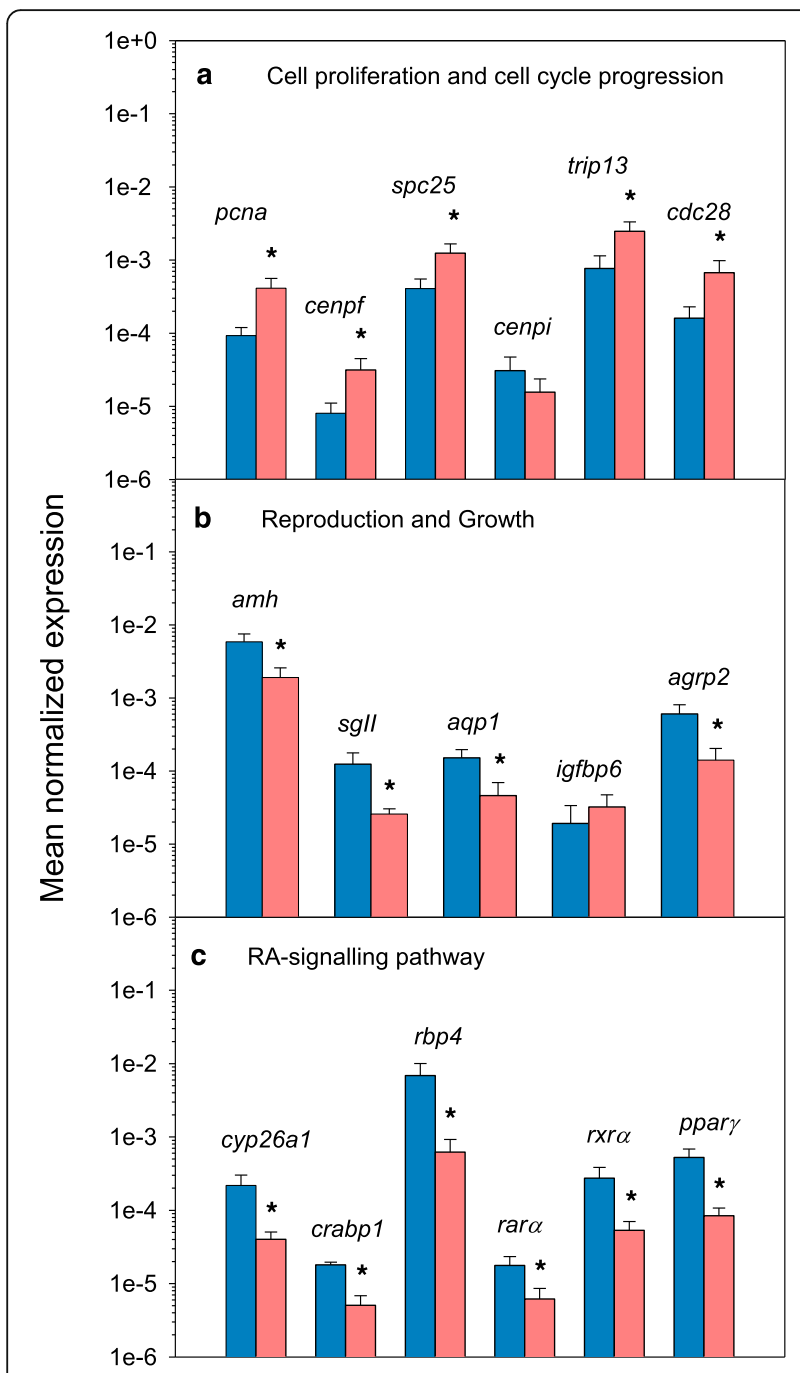

Fig. $4 \mathrm{qPCR}$ results for genes differentially expressed in the microarray during the onset of puberty in the European sea bass. Genes were selected according to their relevance in different reproductive events. a Genes involved in cell proliferation and cell cycle progression; proliferating cell nuclear antigen (pcna), centromere protein I (cenpi), spindle pole body component 25 (spc25), centromere protein $\mathrm{f}(\mathrm{cenpf})$, thyroid hormone receptor interactor 13 (trip 13), and cdc28 protein kinase $(c d c 28)$. b Genes involved in reproduction and growth; antimüllerian hormone (amh), aquaporin 1 (aqp1), secretogranin II (sg/f), agouti-related protein 2 (agrp2), insulin-like growth factor binding protein 6 (igfbp6). c Genes involved in the RA signalling pathway: RA-metabolizing enzyme cytochrome P450 26a1 (cyp26a1), retinol binding protein 4 (rbp4), RA-binding protein (crabp 1). This group also includes three RA-nuclear receptors, RA receptor alpha (rara), retinoid $X$ receptor alpha (rxra), peroxisome proliferator-activated receptor gamma (ppany) due to their relevance in this pathway. The stage-specific expression levels were normalized to those of the constitutively expressed 185 rRNA gene in each sample. Expression data are shown as mean normalized expression + SEM. Yaxis is represented in logarithmic scale for easier visualization. For each gene, bars on the left (blue) correspond to stage I testes and bars on the right (red) to stage II testes

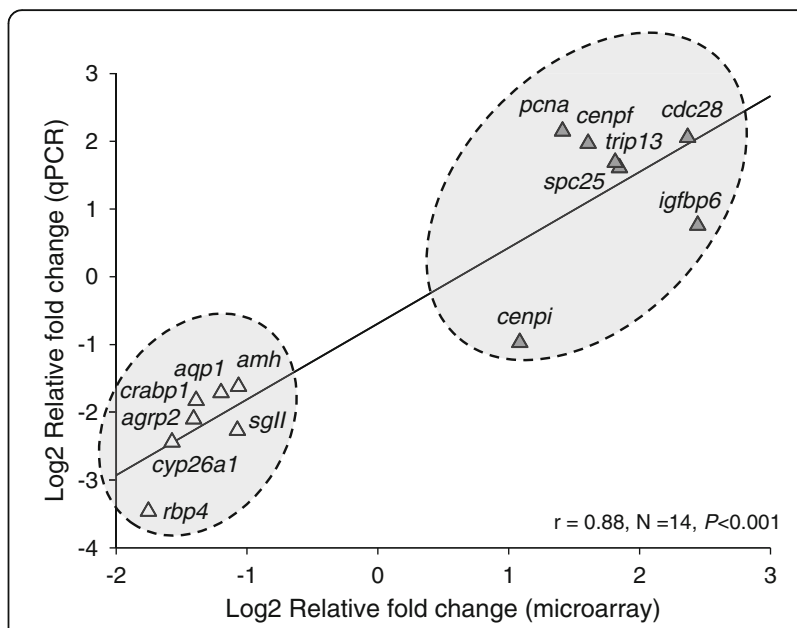

Fig. 5 Correlation between microarray and $\mathrm{QPCR}$ results. Fold change (FC) induction values of the different gene transcripts are plotted as $\log 2$ values of the relative fold change. The $X$-axis represent microarray data whereas the $Y$ axis corresponds to $\mathrm{GPCR}$ data. The regression line and the corresponding $r$ coefficient are also represented. For gene symbols and complete gene names see caption of Fig. 4

reduced ability to discriminate between similar transcripts produced by the same locus, paralogs or similar members of large gene families. To circumvent this problem, we cloned the full-length sequence of several selected DEGs and then validated the results with $\mathrm{qPCR}$ obtaining a good correlation between both methods. In addition, the study revealed the complete sequences of some transcripts for the first time in the European sea bass, adding contrasted information to the microarray that was based on EST sequences. However, for other DEGs that were not annotated in the microarray, we could not find any match to reveal their identities in any of the databases searched including Genebank, Ensembl, and Uniprot. The different stages of spermatogenesis (stage I and stage II) used for the study were classified by histology and their corresponding $11 \mathrm{KT}$ levels were further confirmed by EIA, demonstrating that the increase of circulating $11 \mathrm{KT}$ marks the initiation of pubertal development. A similar result was found in other teleosts including eel [56], goldfish [57], zebrafish [16] or trout [58] and $11 \mathrm{KT}$ measured from the mucus of carps was suitable to differentiate males from females $[59,60]$. However, no correlation between $11 \mathrm{KT}$ and gonad developmental stage in either male or female carp could be found [59]. Our results open the possibility to explore the use of $11 \mathrm{KT}$ as a non-lethal marker for the onset of puberty in this species helping to manage the fish farms stocks to separate precocious from non-precocious European sea bass males.

The transcriptome response revealed that cell proliferation, cell cycle and meiosis progression were pathways preferentially affected during the onset of male puberty. The spindle assembly checkpoint (SAC) is a control 


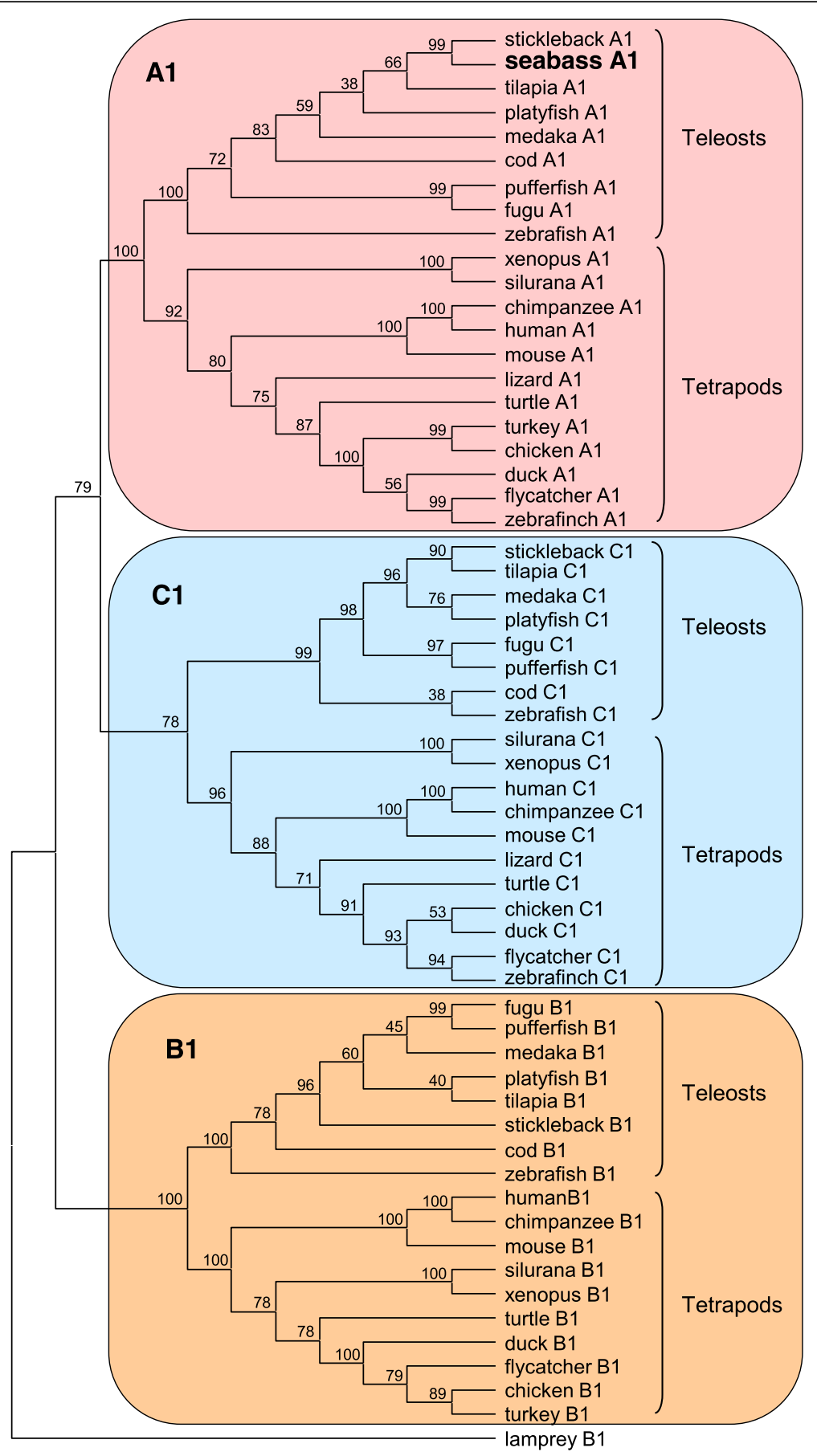

Fig. 6 Phylogenetic tree of Cyp26 family proteins. The tree was constructed using the Neighbor-Joining method. The bootstrap consensus tree inferred from 1000 replicates is taken to represent the evolutionary history of the taxa analysed. The percentage of times each branching was obtained out of the 1000 bootstraps is shown next to the nodes. The evolutionary distances were computed using the Poisson correction method. All positions containing alignment gaps and missing data were eliminated in pairwise sequence comparisons (pairwise deletion option). Phylogenetic analyses were conducted in MEGA4 [49]. A cyp26b1-like isoform from lamprey was used as outgroup to root the tree. GenBank/ Ensembl accession numbers of the sequences used to generate the tree appear listed in Additional file 7

mechanism of dividing cells that ensures the correct segregation of chromosomes by blocking cell cycle progression until kinetochores are properly connected to the spindle [61]. In our study, several genes coding for SAC proteins (bub3) and SAC protein regulators (mad2l1bp and $t t k$ ), were upregulated in stage II testes as well as other important kinetochore-associated transcripts such as $n d c 80, \operatorname{spc} 25$, aurkb and $c d c 28$ (Additional file 2). 


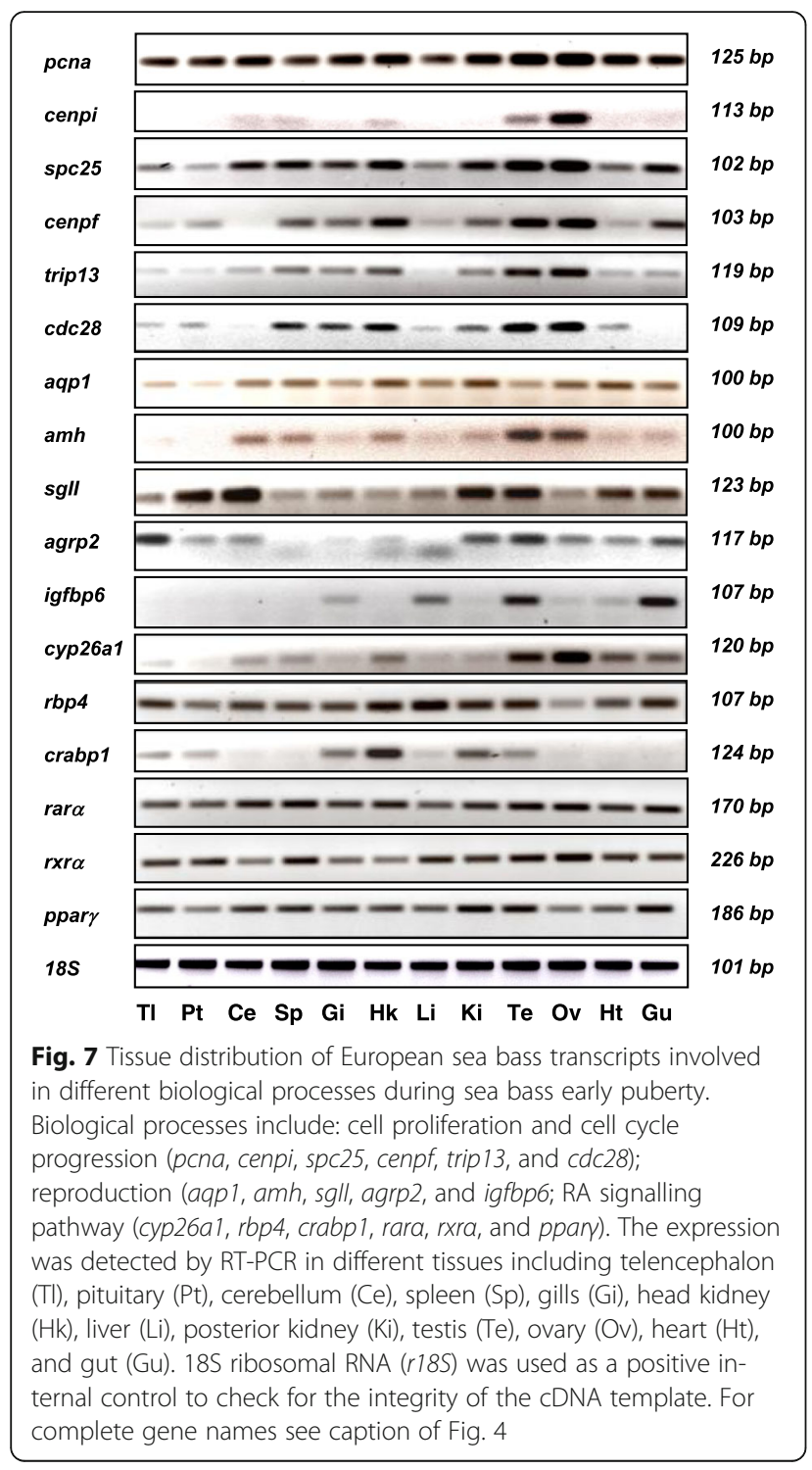

$n d c 80$ and $\operatorname{spc} 25$ code for essential proteins of the Ndc80 complex, needed for SAC activity [62] while aurkb (aurora kinase b) controls kinetochore orientation during meiosis [63]. Defects in $c d c 28$ function result in delays in the exit from mitosis and in meiosis impairment among others [64]. Transcripts coding for centromere proteins like cenph, cenpi or cenpf, were also upregulated. In the case of cenpi, in addition to its role in centromere formation, it is involved in the response of gonadal tissues to Fsh [65]. The upregulation of cenpi in stage II coincides with the initiation of the gradual increase in Fsh plasma levels in European sea bass during early spermatogenesis $[1,33]$. This is in line with the role of Fsh inducing germ cell proliferation and marks the onset of spermatogenesis through the activation of spermatogenesis-related genes [34]. Several transcripts like sycp 2 and syce1, coding for proteins of the synaptonemal complex and trip13, required for the completion of meiosis [66], were upregulated in stage II testes. Moreover, $p c n a$, essential for DNA replication and a molecular marker of dividing cells [67], also increased during the onset of spermatogenesis in agreement with the active mitosis of spermatogonia typical of this period [18]. The role of pcna in the proliferation of germ cells has been described in several teleosts and is currently used in a number of fish species as a marker of spermatogenesis progression [2]. All these results are supported by the analysis of affected biological pathways (Table 2) that showed higher expression of genes involved in cellular processes, particularly those involved in cell cycle, meiosis and DNA replication and repair. In addition, several signalling pathways involved in testicular development such as Wnt, MAPK, hedgehog and TGF beta signalling pathways [68] were altered during early puberty in European sea bass. Altogether, the upregulation of the above mentioned genes is indicative of an active period of mitosis, reflect the need for a tight control of the correct division of the cells, and constitutes an indicator for the progression of meiosis typical of this stage.

A second group of DEGs includes those implicated in reproduction and growth. Amh is involved in gonadal development and steroidogenesis in vertebrates and induces the regression of müllerian ducts in mammals during male embryogenesis [69]. Although fish do not have müllerian ducts, amh homologues have been identified in several teleosts [70], suggesting evolutionary conserved functions for this gene. The role of Amh as a meiosis inhibiting factor was first shown in eels [71] and recently in zebrafish [16], induced by the increase of circulating $11 \mathrm{KT}$ that blocked amh expression facilitating spermatogenesis completion. In teleosts, amh has a key role in early testicular maturation with highest levels in prespermatogenic testis and lowest during spawning [72]. In European sea bass, administration of recombinant Fsh induced spermatogonial proliferation and differentiation into spermatocytes, due to the increase of $11 \mathrm{KT}$ levels and the concomitant suppression of amh expression [34]. Moreover, amh mRNA and protein expression was detected in Sertoli cells of prepubertal European sea bass, and the signal decreased during spermatogenesis [73]. Our results showed a decrease of amh levels during early spermatogenesis in agreement with its role as an inhibitor of spermatogenesis progression. This is supported by the increase of pcna, cenpi and $11 \mathrm{KT}$ levels in the same testicular stage. Likewise, a downregulation of amh during the reproductive cycle has been found in the testicular transcriptome of rainbow trout [12] and in precocious Atlantic salmon [74], further demonstrating that the inhibitory effect of Amh of the onset of puberty can 
be extended to all fish species so far studied. In addition, the study of the biological pathways affected during the onset of puberty, also show the importance of amh in several signalling pathways including those of TGF beta, hippo and cAMP [68]. Few studies are available for $s g I I$ in fish, apart from those in goldfish [75-77]. SgII is widely distributed in secretory granules of neurons and endocrine cells [78] and is the precursor of secretoneurin, a bioactive neuropeptide capable to induce Lh secretion [75, 77]. Our results show low sgII expression by the onset of spermatogenesis, in agreement with the low Lh levels found at this stage in the European sea bass $[1,30]$. It would be very interesting to determine whether sgII, and therefore secretoneurin, also increase during later stages of spermatogenesis, coinciding with the surge of Lh, to experimentally test this hypothesis. Pioneering studies in sea bream point at the relevance of aquaporin 1 (aqp1) in fish reproduction due to its role in water intake during oocyte hydration prior to spawning [79] and in the activation of sperm motility during the last stages of spermatogenesis [80, 81]. Our results show low aqp1 levels during early spermatogenesis, in agreement with its prominent role in sperm maturation during the last stages of spermatogenesis. Agrp2 (agouti-related protein 2) is an orexigenic peptide with a key role in the regulation of energy balance in mammals [82] and fish [83]. In this regard, our study shows that the lipid metabolism pathway where agrp 2 was included was affected during the early stages of pubertal development further supporting its role in energy balance. A direct link between leptin, the most powerful orexigenic neuropeptide in fish [84], and the AGRP system has been suggested in European sea bass males [8]. Moreover, abundant Agrp expression was found in mouse pachytene-spermatocytes and immunohistochemistry revealed that Agrp co-localized with Scp3, a meioticspecific protein of the synaptonemal complex [85]. Although agrp 2 has been characterized in European sea bass testis [86], this is the first time its involvement in spermatogenesis is suggested, possibly due to the specific energy requirements during spermatogenesis and the decrease in food intake. This is in agreement with the downregulation of agrp 2 in European sea bass brain after long-term fasting [86] and its decrease in testis during early spermatogenesis (present study), and link the appetite and growth system with reproduction [87]. Moreover, a transcriptomic study of trout testis revealed that Fsh administration induced the increase of igfbp6 [88]. This strong Fshinduced upregulation was present during early spermatogenesis, including germ cell proliferation and meiosis, and was associated to the effect of the Igf- signalling pathway on spermatogenesis progression [89]. Our results also show a clear upregulation of igfbp6, coinciding with the first stages of pubertal development and the increase of $11 \mathrm{KT}$ plasma levels.

The last group of DEGs is associated with the RAsignalling pathway. RA has been proposed as a meiosis inducing factor in tetrapods including mammals [51], birds [52], amphibians [53] and fish [4, 5, 54, 90]. Two transcripts coding for binding proteins, one in charge of retinol transport (rbp4) through the blood stream and another one (crabp1) in charge of the translocation of RA to the nucleus of the target cells [91] were differentially expressed in European sea bass transcriptome. In addition, cyp26a1, responsible for the degradation of intracellular RA and essential for the maintenance of RA homeostasis [50], was affected. The decrease of cyp26a1 in stage II is associated with a decrease in the translocation and transport of RA brought about by the downregulation of rbp4 and crabp1, in order to maintain the homeostasis of RA that otherwise, and at high levels can be toxic for the cell [92]. In addition, retinol metabolism was one of the affected metabolic pathways found in the present study. It seems thus plausible that in European sea bass, the suppression of RA degradation and the concomitant increase in the availability of RA could be partially responsible for triggering the onset of meiosis. In zebrafish testes, cyp26a1 was expressed in germ cells entering meiosis, while in females, a downregulation was found in oocytes during meiosis resumption [54]. Likewise, in medaka, RA was found to act directly on Sertoli cells, Leydig cells, and pre-meiotic germ cells with a decrease of cyp26a1 expression by the time of meiosis resumption, whereas in ovaries, RA-transcriptional activity is highest in meiotic oocytes [5]. In addition, in vivo Fsh-injection to pre-spermatogenic zebrafish males induced the onset of spermatogenesis and resulted in changes of several enzymes involved in the RAsignalling pathway, including a decrease in cyp26a1 expression, although no effect was found after ex vivo culture of pre-spermatogenic testes with Fsh [17]. Moreover, the administration of an inhibitor of RA synthesis in combination with a deficient diet of vitamin A (a precursor of RA) to adult zebrafish also induced a downregulation of cyp26a1, most likely to increase intracellular RA levels, although spermatogenesis was still disrupted, and fertility compromised [93]. The above mentioned studies suggest that a decrease in cyp26 expression is associated with the onset of spermatogenesis and the initiation of meiosis and prompted us to clone and obtain the full length of its cDNA. The alignment of the deduced protein sequence with other Cyp26 proteins available from other vertebrates confirmed its identity as Cyp26a1 revealing slight differences in homology among teleosts, further supporting their high conservation due 
to its pivotal role controlling RA levels. The tree shows the presence of a common ancestor cyp26 protein, strengthening the hypothesis of an independent functionalization of its coding gene prior to the two rounds of genome duplication in vertebrates [54]. Moreover, the study of the promoter showed the presence of binding sites for cell cycle regulators and for RA nuclear receptors including Ppar, Rxr and Rar, and also DR1 and DR5 sites (RA-responsive elements) indicating the role of RA, via the interaction with its nuclear receptors, in the regulation of cyp26a1 transcription in the European sea bass. A similar result has been shown for the cyp26a1 promoter in zebrafish [94, 95] and medaka [5], although the development of functional studies is clearly needed to confirm the capability of RA to induce the regulation of cyp26a1 in the European sea bass. To gain more insight on the importance of the RA-signalling pathway in meiosis we studied the expression of several nuclear receptors involved in RA binding including rar $\alpha$, raxr $\alpha$, and ppary. The receptors appeared ubiquitously expressed and at similar levels in all the tissues studied, reflecting the general actions and the importance of RA in numerous biological processes throughout evolution [96] and its involvement in the proliferation and differentiation of many cell types [97].

\section{Conclusion}

To the best of our knowledge, this is the first transcriptomic study focussed on the early stages of puberty, and aimed at the identification of molecular and endocrine signals triggering the start of the initial spermatogenic wave in European sea bass. Increases in androgen plasma levels, particularly $11 \mathrm{KT}$, mark the transition between testicular stage I and stage II. This opens the possibility to explore the use of $11 \mathrm{KT}$ in the management of European sea bass stocks in aquaculture farms to separate precocious from non-precocious males. The study improved the annotation of different genes of the microarray and helped to increase the knowledge of several mechanisms and biological pathways involved in early stages of puberty. Altogether, the study shows that the onset of spermatogenesis is characterized by the activation of genes involved in cell cycle progression and division including mitosis and meiosis. The differential expression of several components of the RA-signalling pathway suggests their important role in the onset of meiosis. This work lays the foundation for an in-depth study of the RA-signalling signalling pathway and its role in the onset of meiosis in fish. A future increase in the sequencing of the European sea bass gonad transcriptome and the use of RNA-seq technologies will help to shed light on the molecular pathways involved in relevant aspects of the reproductive process of this economically important species and will aid to develop comparative studies on gonadal differentiation and maturation in teleosts.

\section{Additional files}

Additional file 1: A table containing $\mathrm{qPCR}$ primer characteristics and different features to calculate the efficiency of the primers in the amplification reactions (word format, doc). (DOC $52 \mathrm{~kb}$ )

Additional file 2: A table containing all the DEGs found in the microarray during the onset of European sea bass puberty. The searchable excel file contains the probe ID and primary accession numbers assigned in the custom European sea bass microarray to all differentially expressed genes. The $p$-value and adjusted $p$-value are also included, as well as the fold change and the regulation (stage I versus stage II) obtained after comparison of sea bass testes during the onset of puberty. The annotation information is given in the gene description column that reported the presence of 153 nonannotated sequences from a total of 315 differentially expressed genes, and in the gene description column containing a brief explanation of each gene

function. Finally, a column with the assigned GO-terms is also included (excel format, xIs). (XLS $144 \mathrm{~kb}$ )

Additional file 3: Gene abbreviation glossary of the most relevant DEGs found in the microarray during the onset of European sea bass puberty. A table containing all the DEGs that appear specifically mentioned in the study out of the 315 DEGs found after microarray hybridizations and qPCR validations (word format, doc). (DOC $51 \mathrm{~kb}$ )

Additional file 4: Principal component analysis of the transcriptomic results from the microarray hybridizations. Each data point corresponds to a pool of RNAs from the testis of six different fish. Blue circles correspond to RNAs from testis in developmental stage I and red circles to RNAs from testis in stage II. Numbers between brackets represent the percentage of variation explained by each component; i.e. component 1 (PC1) and component 2 (PC2) (powerpoint format, .ppt). (PPT 108 kb)

Additional file 5: Distribution by GO-terms of the differentially expressed genes (DEGs) during the onset of European sea bass puberty. The multi-level pie graph classified the DEGs according to their GO-terms in three main categories, including: A; Biological processes (cutoff value $=10$ sequences), $B$; molecular function (cutoff value $=5$ sequences), and $C$; cell component (cutoff value $=5$ sequences). The number of genes found in each GO-term appear written between parentheses (powerpoint format, .ppt). (PPT 147 kb)

Additional file 6: A table containing the microarray versus $\mathrm{QPCR}$ fold change (FC) expression values for 14 genes differentially expressed in the European sea bass transcriptome during early stages of pubertal development (word format, doc). (DOC $54 \mathrm{~kb}$ )

Additional file 7: A table containing all the protein sequences used to generate the phylogenetic tree for cyp26 (word format, doc). (DOCX $16 \mathrm{~kb}$ )

Additional file 8: Transcription factor binding sites along the European sea bass cyp $26 a 1$ promoter sequence (1500 bp). The searchable excel file contains different columns reporting information of the family of transcription factor, information on the matrix, the position of the binding site in the sequence (start and end of the sequence), the identification of the DNA strand (+ or -), the similarity of the core and the matrix sequences and finally the sequence (excel format, .xIs) (XLS 39 kb)

\section{Acknowledgements}

We thank Sebastián Boltaña, Nerea Roher and Benjamí Piña for technical support on microarray processing data.

\section{Funding}

This work was supported by Aquagenomics project (CSD2007-0002) from the Spanish Ministry of Science and Innovation to SZ and a MICINN project (AGL2011-28890) to AG. PM was supported by a grant from the University of Antofagasta MECE2 (ANT0806). 


\section{Availability of data and materials}

The complete design was deposited at the Gene Expression Omnibus NCBI database GSE47400 https://www.ncbi.nlm.nih.gov/geo/query/ acc.cgi?token=exgnmkgcfbwnhkp\&acc=GSE47400 and the platform that validates the microarray can be found at GPL13443.

\section{Authors' contributions}

$M B, A G$ and $S Z$ designed the study; PM, BC and MB conducted the experiments, performed the molecular biology studies and the statistical and microarray analyses. MB drafted the initial manuscript; MB, PM, BC, AG and SZ wrote the manuscript. All authors read and approved the final manuscript.

\section{Competing interests}

The authors declare that they have no competing financial and non-financial interests.

\section{Consent for publication}

Not applicable

\section{Ethics approval and consent to participate}

Fish were treated in agreement with the Spanish regulations (Royal Decree Act 53/2013) and the European legislation (2010/63 EU) concerning the protection of animals used for experimental and other scientific purposes. The experiments were performed following the approval from the institutional regulations on animal experimental handling review board from the IATS-CSIC and from the CSIC ethics committee (project number CSD2007-002). All steps were taken to reduce suffering of the animals.

\section{Publisher's Note}

Springer Nature remains neutral with regard to jurisdictional claims in published maps and institutional affiliations.

\begin{abstract}
Author details
${ }^{1}$ Instituto de Acuicultura de Torre la Sal, Consejo Superior de Investigaciones Científicas (IATS-CSIC), Ribera de Cabanes, 12595 Castellón, Spain. ${ }^{2}$ Instituto de Ciencias del Mar, Consejo Superior de Investigaciones Científicas (ICM-CSIC), Passeig Maritim 37-49, 08003 Barcelona, Spain. ${ }^{3}$ Present address: Universidad de Antofagasta, Avda Angamos 601, Antofagasta, Chile. ${ }^{4}$ Present address: UCL Great Ormond Street Institute of Child Health, 30 Guilford Street, London, WC1N 1EH, UK.
\end{abstract}

Received: 7 November 2016 Accepted: 25 May 2017 Published online: 05 June 2017

\section{References}

1. Carrillo M, Espigares F, Felip A, Escobar S, Molés G, Rodríguez R, et al. Updating control of puberty in male European sea bass: a holistic approach. Gen Comp Endocrinol. 2015;221:42-53.

2. Schulz RW, de França LR, Lareyre J-J, LeGac F, Chiarini-Garcia H, Nobrega RH, et al. Spermatogenesis in fish. Gen Comp Endocrinol. 2010;165(3):390-411.

3. Nóbrega R, Batlouni S, França L. An overview of functional and stereological evaluation of spermatogenesis and germ cell transplantation in fish. Fish Physiol Biochem. 2009;35(1):197-206.

4. Feng R, Fang L, Cheng $Y$, He $X$, Jiang W, Dong R, et al. Retinoic acid homeostasis through aldh1a2 and cyp26a1 mediates meiotic entry in Nile tilapia (Oreochromis niloticus). Sci Rep. 2015;5:10131.

5. Adolfi MC, Herpin A, Regensburger M, Sacquegno J, Waxman JS, Schartl M. Retinoic acid and meiosis induction in adult versus embryonic gonads of medaka. Sci rep. 2016;6:34281.

6. Griswold MD. The central role of Sertoli cells in spermatogenesis. Semin Cell dev Biol. 1998;9:411-6.

7. Zohar Y, Muñoz-Cueto JA, Elizur A, Kah O. Neuroendocrinology of reproduction in teleost fish. Gen Comp Endocrinol. 2010;165(3):438-55.

8. Escobar S, Rocha A, Felip A, Carrillo M, Zanuy S, Kah O, et al. Leptin recepto gene in the European sea bass (Dicentrarchus labrax): cloning, phylogeny, tissue distribution and neuroanatomical organization. Gen Comp Endocrinol. 2016;229:100-11.
9. Taranger GL, Carrillo M, Schulz RW, Fontaine P, Zanuy S, Felip A, et al Control of puberty in farmed fish. Gen Comp Endocrinol. 2010;165(3): 483-515.

10. Schulz RW, Miura T. Spermatogenesis and its endocrine regulation. Fish Physiol Biochem. 2002;26(1):43-56.

11. Miura T, Miura Cl. Molecular control mechanisms of fish spermatogenesis. Fish Physiol Biochem. 2003;28(1-4):181-6.

12. Rolland AD, Lareyre J-J, Goupil A-S, Montfort J, Ricordel M-J, Esquerré D, et al. Expression profiling of rainbow trout testis development identifies evolutionary conserved genes involved in spermatogenesis. BMC Genomics. 2009;10(1):546.

13. Chauvigné F, Verdura S, Mazón MJ, Duncan N, Zanuy S, Gómez A, et al. Follicle-stimulating hormone and luteinizing hormone mediate the androgenic pathway in Leydig cells of an evolutionary advanced teleost. Biol Reprod. 2012;87(2):1-11.

14. García-López A, Bogerd J, Granneman JC, van Dijk W, Trant JM, Taranger GL, et al. Leydig cells express follicle-stimulating hormone receptors in African catfish. Endocrinol. 2009;150(1):357-65.

15. García-López A, de Jonge H, Nóbrega RH, de Waal PP, van Dijk W, Hemrika W, et al. Studies in zebrafish reveal unusual cellular expression patterns of gonadotropin receptor messenger ribonucleic acids in the testis and unexpected functional differentiation of the gonadotropins. Endocrinol. 2010;151(5):2349-60.

16. Skaar K, Nobrega R, Magaraki A, Olsen L, Schulz R, Male R. Proteolytically activated, recombinant anti-müllerian hormone inhibits androgen secretion, proliferation, and differentiation of spermatogonia in adult zebrafish testis organ cultures. Endocrinol. 2011;152(9):3527-40.

17. Crespo D, Assis LH, Furmanek T, Bogerd J, Schulz RW. Expression profiling identifies Sertoli and Leydig cell genes as Fsh targets in adult zebrafish testis. Mol Cell Endocrinol. 2016:437:237-51.

18. Begtashi I, Rodríguez L, Moles G, Zanuy S, Carrillo M. Long-term exposure to continuous light inhibits precocity in juvenile male European sea bass (Dicentrarchus labrax, L.). I. Morphological aspects. Aquaculture. 2004;241(1): 539-59.

19. Zanuy S, Carrillo M, Felip A, Rodríguez L, Blázquez M, Ramos J, et al. Genetic hormonal and environmental approaches for the control of reproduction in the European sea bass (Dicentrarchus labrax L.). Aquaculture. 2001;202(3): 187-203.

20. Felip A, Zanuy S, Carrillo M. Comparative analysis of growth performance and sperm motility between precocious and nonprecocious males in the European sea bass (Dicentrarchus labrax, L.). Aquaculture. 2006;256(1):570-8.

21. Felip A, Zanuy S, Muriach B, Cerdá-Reverter JM, Carrillo M. Reduction of sexual maturation in male Dicentrarchus labrax by continuous light both before and during gametogenesis. Aquaculture. 2008:275:347-55.

22. Rodríguez L, Begtashi I, Zanuy S, Carrillo M. Long-term exposure to continuous light inhibits precocity in European male sea bass (Dicentrarchus labrax, L.): hormonal aspects. Gen Comp Endocrinol. 2005:140(2):116-25.

23. Rodríguez L, Carrillo M, Sorbera LA, Zohar Y, Zanuy S. Effects of photoperiod on pituitary levels of three forms of $\mathrm{GnRH}$ and reproductive hormones in the male European sea bass (Dicentrarchus labrax, L.) during testicular differentiation and first testicular recrudescence. Gen Comp Endocrinol. 2004;136(1):37-48

24. Alvarado M, Carrillo M, Felip A. Expression of kisspeptins and their receptors, gnrh-1/gnrhr-II-1a and gonadotropin genes in the brain of adult male and female European sea bass during different gonadal stages. Gen Comp Endocrinol. 2013:187:104-16.

25. Escobar S, Felip A, Gueguen M-M, Zanuy S, Carrillo M, Kah O, et al. Expression of kisspeptins in the brain and pituitary of the European sea bass (Dicentrarchus labrax). J Comp Neurol. 2013;521(4):933-48.

26. Escobar S, Servili A, Espigares F, Gueguen M-M, Brocal I, Felip A, et al. Expression of kisspeptins and kiss receptors suggests a large range of functions for kisspeptin systems in the brain of the European sea bass. PLoS One. 2013;8(7):e70177

27. Felip A, Zanuy S, Pineda R, Pinilla L, Carrillo M, Tena-Sempere M, et al. Evidence for two distinct KiSS genes in non-placental vertebrates that encode kisspeptins with different gonadotropin-releasing activities in fish and mammals. Mol Cell Endocrinol. 2009;312(1):61-71.

28. González-Martínez D, Zmora N, Mañanos E, Saligaut D, Zanuy S, Zohar Y, et al. Immunohistochemical localization of three different prepro-GnRHs in 
the brain and pituitary of the European sea bass (Dicentrarchus labrax) using antibodies to the corresponding GnRH-associated peptides. J Comp Neurol. 2002:446(2):95-113.

29. González-Martínez D, Madigou T, Mañanos E, Cerdá-Reverter JM, Zanuy S, Kah O, et al. Cloning and expression of gonadotropin-releasing hormone receptor in the brain and pituitary of the European sea bass: an in situ hybridization study. Biol Reprod. 2004;70(5):1380-91.

30. Rocha A, Zanuy S, Carrillo M, Gómez A. Seasonal changes in gonadal expression of gonadotropin receptors, steroidogenic acute regulatory protein and steroidogenic enzymes in the European sea bass. Gen Comp Endocrinol. 2009;162(3):265-75.

31. Mateos J, Mañanós EL, Swanson P, Carrillo M, Zanuy S. Purification of luteinizing hormone $(\mathrm{LH})$ in the sea bass (Dicentrarchus labrax) and development of a specific immunoassay. Ciencias Marinas. 2006;32(2): 271-83.

32. Molés G, Gómez A, Carrillo M, Rocha A, Mylonas CC, Zanuy S. Determination of Fsh quantity and bioactivity during sex differentiation and oogenesis in European sea bass. Biol Reprod. 2011;85(4):848-57.

33. Molés G, Gómez A, Carrillo M, Zanuy S. Development of a homologous enzyme-linked immunosorbent assay for European sea bass FSH. Reproductive cycle plasma levels in both sexes and in yearling precocious and non-precocious males. Gen Comp Endocrinol. 2012;176(1):70-8.

34. Mazón MJ, Gómez A, Yilmaz O, Carrillo M, Zanuy S. Administration of follicle-stimulating hormone in vivo triggers testicular recrudescence of juvenile European sea bass (Dicentrarchus labrax). Biol Reprod. 2014; 90(1):6. 1-10

35. Mazón MJ, Molés G, Rocha A, Crespo B, Lan-Chow-Wing O, Espigares F, et al. Gonadotropins in European sea bass: endocrine roles and biotechnological applications. Gen Comp Endocrinol. 2015;221:31-41.

36. Prat F, Zanuy S, Carrillo M, De Mones A, Fostier A. Seasonal changes in plasma levels of gonadal steroids of sea bass, Dicentrarchus labrax L. Gen Comp Endocrinol. 1990;78(3):361-73.

37. Blázquez M, González A, Papadaki M, Mylonas C, Piferrer F. Sex-related changes in estrogen receptors and aromatase gene expression and enzymatic activity during early development and sex differentiation in the European sea bass (Dicentrarchus labrax). Gen Comp Endocrinol. 2008;158(1): 95-101.

38. Crespo B, Gómez A, Mazón MJ, Carrillo M, Zanuy S. Isolation and characterization of Ffl and Gsdf family genes in European sea bass and identification of early gonadal markers of precocious puberty in males. Gen Comp Endocrinol. 2013;191:155-67.

39. Tine M, Kuhl H, Gagnaire P-A, Louro B, Desmarais E, Martins RS, et al. European sea bass genome and its variation provide insights into adaptation to euryhalinity and speciation. Nat Commun. 2014:5:5770.

40. McDowell E, Trump B. Histologic fixatives suitable for diagnostic light and electron microscopy. Arch Pathol Lab Med. 1976;100(8):405-14.

41. Bennett HS, Wyrick AD, Lee SW, McNeil JH. Science and art in preparing tissues embedded in plastic for light microscopy, with special reference to glycol methacrylate, glass knives and simple stains. Stain Tech. 1976;51(2): 71-97.

42. Espigares F, Rocha A, Molés G, Gómez A, Carrillo M, Zanuy S. New insights into the factors mediating the onset of puberty in sea bass. Gen Comp Endocrinol. 2015:224:176-85.

43. Conesa A, Götz S, García-Gómez JM, Terol J, Talón M, Robles M. Blast2GO: a universal tool for annotation, visualization and analysis in functional genomics research. Bioinformatics. 2005;21(18):3674-6.

44. Müller PY, Janovjak H, Miserez AR, Dobbie Z. Processing of gene expression data generated by quantitative real-time RT-PCR. BioTechniques. 2002;32: 1372-9.

45. Mitter K, Kotoulas G, Magoulas A, Mulero V, Sepulcre P, Figueras A, et al. Evaluation of candidate reference genes for QPCR during ontogenesis and of immune-relevant tissues of European seabass (Dicentrarchus labrax). Comp Biochem Physiol B: Biochem Mol Biol. 2009;153(4):340-7.

46. Fuster G, Vicente R, Coma M, Grande M, Felipe A, Pinto GV. One-step reverse transcription polymerase chain reaction for semiquantitative analysis of mRNA expression. Methods Find exp Clin Pharmacol. 2002;24(5):253-9.

47. Zuckerkandl E, Pauling L. Evolutionary divergence and convergence in proteins. In: Bryson V, Vogel HJ, editors. Evolving genes and proteins. New York: Academic Press; 1965. p. 97-166.

48. Saitou N, Nei M. The Neighbor-Joining method - a new method for reconstructing Phylogenetic trees. Mol Biol Evol. 1987;4(4):406-25.
49. Tamura K, Dudley J, Nei M, Kumar S. MEGA4: molecular evolutionary genetics analysis (MEGA) software version 4.0. Mol Biol Evol. 2007;24(8): 1596-9.

50. White JA, Beckett-Jones B, Guo Y-D, Dilworth FJ, Bonasoro J, Jones G, et al, CDNA cloning of human retinoic acid-metabolizing enzyme (hP450RAl) identifies a novel family of cytochromes P450 (CYP26). J Biol Chem. 1997; 272(30):18538-41.

51. Bowles J, Koopman P. Retinoic acid, meiosis and germ cell fate in mammals. Development. 2007;134(19):3401-11.

52. Smith CA, Roeszler KN, Bowles J, Koopman P, Sinclair AH. Onset of meiosis in the chicken embryo; evidence of a role for retinoic acid. BMC dev Biol. 2008;8:85.

53. Wallacides A, Chesnel A, Chardard D. Flament S, Dumond H. Evidence for a conserved role of retinoic acid in urodele amphibian meiosis onset. Dev Dyn. 2009:238(6):1389-98.

54. Rodríguez-Marí A, Cañestro C, BreMiller RA, Catchen JM, Yan Y-L, Postlethwait JH. Retinoic acid metabolic genes, meiosis, and gonadal sex differentiation in zebrafish. PLoS One. 2013;8(9):e73951.

55. Relógio A, Schwager C, Richter A, Ansorge W, Valcárcel J. Optimization of oligonucleotide-based DNA microarrays. Nucleic Acids res. 2002; 30(11):e51.

56. Miura T, Yamauchi $K$, Takahashi H, Nagahama Y. Hormonal induction of all stages of spermatogenesis in vitro in the male Japanese eel (Anguilla japonica). P Natl Acad Sci USA. 1991;88(13):5774-8.

57. Kobayashi M, Aida K, Stacey NE. Induction of testis development by implantation of 11-ketotestosterone in female goldfish. Zool Sci. 1991;8(2): 389-93.

58. Rolland AD, Lardenois A, Goupil A-S, Lareyre J-J, Houlgatte R, Chalmel F, et al. Profiling of androgen response in rainbow trout pubertal testis: relevance to male gonad development and spermatogenesis. PLoS One. 2013;8(1):e53302.

59. Schultz D, Perez N, Tan CK, Mendez A, Capo T, Snodgrass D, et al. Concurrent levels of 11-ketotestosterone in fish surface mucus, muscle tissue and blood. J Appl Ichthyol. 2005;21(5):394-8.

60. Schultz D, Perez N, Mendez A, Snodgrass D, Serafy J, Prince E, et al. Tracking gender factors in fish surface mucus: temporal patterns in individual koi (Cyprinus carpio). J Appl Ichthyol. 2007;23(2):184-8.

61. Lara-Gonzalez P, Westhorpe FG, Taylor SS. The spindle assembly checkpoint. Curr Biol. 2012;22(22):R966-80.

62. Kline-Smith SL, Sandall S, Desai A. Kinetochore-spindle microtubule interactions during mitosis. Curr Opin Cell Biol. 2005;17(1): 35-46.

63. Monje-Casas F, Prabhu VR, Lee BH, Boselli M, Amon A. Kinetochore orientation during meiosis is controlled by aurora $B$ and the monopolin complex. Cell. 2007;128(3):477-90.

64. Mendenhall MD, Hodge AE. Regulation of Cdc28 cyclin-dependent protein kinase activity during the cell cycle of the yeast Saccharomyces cerevisiae. Microbiol Mol Biol R. 1998;62(4):1191-243.

65. Slegtenhorst-Eegdeman K, Post M, Baarends W, Themmen A, Grootegoed J. Regulation of gene expression in Sertoli cells by follicle-stimulating hormone (FSH): cloning and characterization of LRPR1, a primary response gene encoding a leucine-rich protein. Mol Cell Endocrinol. 1995:108(1):115-24

66. Li X, Schimenti JC. Mouse pachytene checkpoint 2 (trip13) is required for completing meiotic recombination but not synapsis. PLoS Genet. 2007;3(8):e130.

67. Kelman Z. PCNA: structure, functions and interactions. Oncogene. 1997; 14(6):629-40.

68. Windley SP, Wilhelm D. Signaling pathways involved in mammalian sex determination and gonad development. Sex dev. 2015;9(6):297-315.

69. Josso N, Picard J, Rey R, Di Clemente N. Testicular anti-Müllerian hormone: history, genetics, regulation and clinical applications. Pediatric Endocrinol Rev. 2006:3(4):347-58

70. Pfennig F, Standke A, Gutzeit HO. The role of Amh signaling in teleost fish-multiple functions not restricted to the gonads. Gen Comp Endocrinol. 2015;223:87-107.

71. Miura T, Miura C, Konda Y, Yamauchi K. Spermatogenesis-preventing substance in Japanese eel. Development. 2002;129(11):2689-97.

72. Wu G-C, Chiu P-C, Lyu Y-S, Chang C-F. The expression of amh and amhr2 is associated with the development of gonadal tissue and sex change in the protandrous black porgy, Acanthopagrus Schlegeli. Biol Reprod. 2010;83(3): 443-53. 
73. Rocha A, Zanuy S, Gómez A. Conserved anti-Müllerian hormone: antiMüllerian hormone type-2 receptor specific interaction and intracellular signaling in Teleosts. Biol Reprod. 2016;87(2):35. 31-11

74. Guiry A, Flynn D, Hubert S, O'Keeffe AM, LeProvost O, White SL, et al. Testes and brain gene expression in precocious male and adult maturing Atlantic salmon (Salmo salar). BMC Genomics. 2010;11(1):211.

75. Blázquez M, Bosma PT, Chang JP, Docherty K, Trudeau VL. Gamma-Aminobutyric acid up-regulates the expression of a novel Secretogranin-II messenger ribonucleic acid in the goldfish pituitary. Endocrinol. 1998;139(12):4870-80.

76. Zhao E, Basak A, Wong AOL, Ko W, Chen A, López GC, et al. The Secretogranin II-derived peptide Secretoneurin stimulates luteinizing hormone secretion from Gonadotrophs. Endocrinol. 2009;150(5):2273-82.

77. Zhao E, Hu H, Trudeau VL. Secretoneurin as a hormone regulator in the pituitary. Regul Peptides. 2010;165(1):117-22.

78. Blázquez M, Shennan Kl. Basic mechanisms of secretion: sorting into the regulated secretory pathway. Biochem Cell Biol. 2000;78(3):181-91.

79. Fabra M, Raldúa D, Bozzo MG, Deen PM, Lubzens E, Cerdá J. Yolk proteolysis and aquaporin-1o play essential roles to regulate fish oocyte hydration during meiosis resumption. Dev Biol. 2006;295(1):250-62.

80. Zilli L, Schiavone R, Chauvigné F, Cerdá J, Storelli C, Vilella S. Evidence for the involvement of aquaporins in sperm motility activation of the teleost gilthead sea bream (Sparus aurata). Biol Reprod. 2009;81(5):880-8.

81. Boj M, Chauvigné F, Zapater C, Cerdá J. Gonadotropin-activated androgendependent and independent pathways regulate aquaporin expression during teleost (Sparus aurata) spermatogenesis. PLoS One. 2015;10(11):e0142512.

82. Girardet C, Butler AA. Neural melanocortin receptors in obesity and related metabolic disorders. BBA- Mol Basis Dis. 2014;1842(3):482-94.

83. Guillot R, Cortés R, Navarro S, Mischitelli M, Garía-Herranz V, Sánchez E, et al. Behind melanocortin antagonist overexpression in the zebrafish brain: a behavioral and transcriptomic approach. Horm Behav. 2016;82:87-100.

84. Volkoff H, Canosa L, Unniappan S, Cerda-Reverter J, Bernier N, Kelly S, et al. Neuropeptides and the control of food intake in fish. Gen Comp Endocrinol. 2005;142(1):3-19.

85. Inntska O, Sözen MA, Dauterive R, Argyropoulos G. Control elements in the neighboring ATPase gene influence spatiotemporal expression of the human agouti-related protein. J Mol Biol. 2009;388(2):239-51.

86. Agulleiro MJ, Cortés R, Leal E, Ríos D, Sánchez E, Cerdá-Reverter JM. Characterization, tissue distribution and regulation by fasting of the agouti family of peptides in the sea bass (Dicentrarchus labrax). Gen Comp Endocrinol. 2014;205:251-9.

87. Reinecke M. Insulin-like growth factors and fish reproduction. Biol Reprod. 2010;82(4):656-61.

88. Sambroni E, Lareyre J-J, Le Gac F. Fsh controls gene expression in fish both independently of and through steroid mediation. PLoS One. 2013;8(10):e76684.

89. Sambroni E, Rolland AD, Lareyre J-J, Le Gac F. Fsh and Lh have common and distinct effects on gene expression in rainbow trout testis. J Mol Endocrinol. 2013;50(1):1-18.

90. Lau E-L, Lee M-F, Chang C-F. Conserved sex-specific timing of meiotic initiation during sex differentiation in the protandrous black porgy Acanthopagrus schlegelii. Biol Reprod. 2013:88(6):150. 151-113

91. Schug TT, Berry DC, Shaw NS, Travis SN, Noy N. Dual transcriptional activities underlie opposing effects of retinoic acid on cell survival. Cell. 2007;129(4):723-33.

92. Chung $S$, Wolgemuth $D$. Role of retinoid signaling in the regulation of spermatogenesis. Cytogenet Genome Res. 2004;105(2-4):189-202.

93. Pradhan A, Olsson PE. Inhibition of retinoic acid synthesis disrupts spermatogenesis and fecundity in zebrafish. Gen Comp Endocrinol. 2015; 217-218:81-91.

94. Hu P, Tian M, Bao J, Xing G, Gu X, Gao X, et al. Retinoid regulation of the zebrafish cyp26a1 promoter. Dev Dyn. 2008;237(12):3798-808.

95. Loudig O, Babichuk C, White J, Abu-Abed S, Mueller C, Petkovich M. Cytochrome P450RAI (CYP26) promoter: a distinct composite retinoic acid response element underlies the complex regulation of retinoic acid metabolism. Mol Endocrinol. 2000;14(9):1483-97.

96. Albalat $\mathrm{R}$. The retinoic acid machinery in invertebrates: ancestral elements and vertebrate innovations. Mol Cell Endocrinol. 2009;313(1):23-35.

97. Mark M, Ghyselinck NB, Chambon P. Function of retinoid nuclear receptors: lessons from genetic and pharmacological dissections of the retinoic acid signaling pathway during mouse embryogenesis. Annu Rev Pharmacol Toxicol. 2006:46:451-80.

\section{Submit your next manuscript to BioMed Central and we will help you at every step:}

- We accept pre-submission inquiries

- Our selector tool helps you to find the most relevant journal

- We provide round the clock customer support

- Convenient online submission

- Thorough peer review

- Inclusion in PubMed and all major indexing services

- Maximum visibility for your research

Submit your manuscript at www.biomedcentral.com/submit
Biomed Central 